\title{
MASSEY UNIVERSITY
}

LIBRARY

\section{Massey Research Online Massey University’s Institutional Repository}

Massey authors: Helen Moewaka Barnes, Tim McCreanor

Anae, M., Moewaka Barnes, H., McCreanor, T., \& Watson, P. (2002). Towards promoting youth mental health in Aotearoa/New Zealand: Holistic "houses" of health. International Journal of Mental Health Promotion, 4(2), 5-14

http://hdl.handle.net/10179/1811

This document is a manuscript (pre-print). Access the published version of this article from the publisher's website:

http://www.ijmhp.co.uk/

Copyright is owned by the author of the paper. Permission is given for a copy to be downloaded by an individual for the purpose of research and private study only. The paper may not be reproduced elsewhere without the permission of the author. 


\title{
Towards promoting youth mental health in Aotearoa/New Zealand: Holistic "houses" of health.
}

\author{
Melanie Anae \\ Helen Moewaka Barnes \\ Tim McCreanor \\ Peter Watson
}

\begin{abstract}
Alcohol \& Public Health Research Unit
Faculty of Medical and Health Sciences

University of Auckland

PB 92019

Auckland
\end{abstract}

Corresponding author: Dr Tim McCreanor, Alcohol \& Public Health Research Unit, email: timm@pl.net 
Towards promoting youth mental health in Aotearoa/New Zealand: Holistic "houses" of health.

Abstract

A study of the literature on mental health promotion suggests that to a far greater extent than 'physical' health concerns, mental health seems to be dominated by the illness focus of established clinical perspectives and practices. In Aotearoa/New Zealand this leaves little in the way of conceptual space or fiscal resources for the development of new preventative possibilities of population-oriented measures focussed on enhancing social and physical environments. Outflanking this unfortunate impasse, indigenous Maori and Samoan (Pacific) conceptual frameworks for health offer holistic theoretical foundations upon which we can work for health through positive development. This paper examines these frameworks and the youth development paradigm to draw out parameters of what might count as healthy youth development in this country.

Keywords: Mental health promotion; youth; Maori; Samoan; Pakeha; New Zealand 


\section{Introduction}

Health promotion has long been the poor cousin of health service provision and clinical/treatment approaches to illness (Hawe and Shiell, 2000; Herron and Trent, 2000). In the field of mental health, this problem is far deeper than it is for health in general and much less has been done to address it, so that mental health promotion exists as an undervalued and under-theorised satellite to the main body of praxis around mental illness (Friedli, 2001; Friedli, 1999; Hart, 1999; Herron and Trent, 2000; MacDonald and O'Hara, 1998). Reflecting the late realization of this situation, public health institutions with responsibility for mental health are now recognizing the increasing significance of mental health promotion as a vital tool in stemming the rising tide of mental illness problems apparent on the global scale (Murray and Lopez, 1996). In Aotearoa/New Zealand the Ministry of Health is working on a national mental health promotion strategy (Ministry of Health, 2001) from within its Public Health portfolio. For young people in this country there are also two related policy initiatives - the youth development strategy (Ministry of Youth Affairs, 2001) and the youth health strategy (Ministry of Health, 1996b) - under way as part of the current shift in the political environment from the radical neoliberalism the past 15 years (Kelsey, 1993) to a market model moderated by social democratic concerns.

This paper is offered as a contribution to these initiatives specifically as they relate to young people, because in the absence of a strong theoretical base, promotion/development programmes of great potential are in danger of remaining marginalised by established Western theorising of mental health. In this paper, we argue that there is existing knowledge that, if used to guide policy development, can avoid this outcome. This includes important developments in indigenous Maori ${ }^{1}$ and

\footnotetext{
${ }^{1}$ Maori are the indigenous people of Aotearoa/NewZealand.
} 
Samoan $^{2}$ models of 'well-being' in Aotearoa/New Zealand and key ideas from the positive youth development paradigm, with some contributions from social epidemiology. On this basis we critique the Western mental illness-oriented theorising that appears to permeate mental health promotion and argue for conceptualising mental health promotion as changing human environments for population mental health gains. We then outline some emerging possibilities drawn from Maori (Durie, 1997; Durie, 1999; Pere, 1997) and Samoan frameworks (Ministry of Health, 1997a; Tamasese et al, 1997) - our holistic houses of health. Finally we consider synergies with positive youth development (Forum for Youth Investment, 2001; Roth and Brooks-Gunn, 2000) for the optimising of human potential in relation to mental health.

\section{Problems and priorities}

The mental health status of New Zealanders is of major importance in social, economic, ethical and political terms (Disley, 1996). Mental health problems have major negative impacts on general health (MacDonald and O'Hara, 1998;

Charlesworth and Nathan, 1987), work (Evans and Repper, 2000; Marcotte and Wilcox-Gok, 2001; Druss et al, 2000), education (Woodward and Fergusson, 2001; Kessler et al., 1995) and on social structures such as families and communities (Albee, 1992; Kessler et al, 1997; Kessler et al, 1998; Wittchen et al, 1998). Mental illness and poor mental health contribute significantly to the burden of disease in society. In New Zealand mental illness statistics (Ministry of Health, 1997d) show prevalence rates from all cause psychiatric morbidity and mortality to be $29 \%$ for the adult population and 25\% for adolescents which are approximately the same levels as

\footnotetext{
${ }^{2}$ There are significant populations of Samoan people in Aoteroa/NewZealand.
} 
for other industrialised countries (Albee, 1992; Charlesworth and Nathan, 1987; Mrazek and Haggerty, 1994; Murray and Lopez, 1996; Stephens, 1998; VicHealth, 1999).

Mental health issues are at the forefront of the health difficulties facing indigenous peoples world wide especially in the wake of colonial processes (Smith, 1998). Ethnic minorities, displaced or migrating between or within countries in reaction to the colonial world order, have been similarly afflicted (Anae, 1998). In Aotearoa/New Zealand, mental health issues have been described as the major health problem facing Maori, the indigenous people (Te Pumanawa Hauora, 1995). Maori have “much higher rates of presentation to crisis, acute and forensic services than non-Maori” (Mental Health Commission, 1998). Maori admissions to psychiatric hospitals have doubled since 1995, Maori admission rates are 40\% higher than non-Maori, and multiple indicators (including suicide, offending and alcohol-related problems) suggest an overall pattern of poor mental health in Maori communities (Health Funding Authority, 1999). The rate of Maori youth suicide was 33.9 per 100,000 compared to the non-Maori rate of 24.2 per 100,000 (Ministry of Health, 1999). Dyall (Dyall, 1997a; Dyall, 1997b) highlights the absence of national data on Maori mental health needs, a likely under-reporting of as much as 30\%, and the increasing prioritisation of mental health by Maori and an orientation to 'by Maori for Maori' approaches.

The mental health of Pacific peoples in New Zealand is also, a matter for concern (Anae, 1999; Tamasese et al, 1997). Studies by Dawson (Dawson, 1988) and Bathgate, (Bathgate, 1994) show that Pacific people have higher rates of readmission to psychiatric institutions than other groups and that there is a higher prevalence of complications arising from late presentation compared with the whole population. 
First admission rates to psychiatric institutions were strongly elevated for Pacific youth (15-24) with schizophrenic disorders and elevated for affective psychoses compared with Palagi ${ }^{3}$ (Bathgate, 1994).

Policy to address these concerns has been developed and now exists in the form of the $\underline{\text { National Mental Health Strategy (Mental Health Commission, 1999), the National }}$ Mental Health Plan (Ministry of Health, 1997c), Kia Tu Kia Puawai (Health Funding Authority, 1999), the National Workplan for Child and Youth Mental Health Services (Health Funding Authority, 2000) and related documents. These policies take the lead in the efforts to raise government targets of service provision to the most "in need" which they define as 3\% of adults and 5\% of children. Yet the data above and Maori and Samoan research (Anae, 1999; Bathgate, 1994; Dawson, 1988; Mental Health Commission, 1998; Tamasese et al, 1997; Te Pumanawa Hauora, 1995) suggest that, given the existing and projected levels of distress, even if these targets are reached it will not have a major impact on the experience of the afflicted or the cost to the wider population. There is a groundswell of awareness from Maori and Pacific communities of the lack of fit of "mainstream" services when attempting to meet the needs of Maori and Pacific peoples in relation to mental illness (Bathgate, 1994; Dyall, 1997a; Dyall, 1997b)

We accept that the burden of mental illness upon individuals, families and communities is dire (Ministry of Health, 1996a) and acknowledge and applaud the efforts and progress made within the treatment and service provision sectors under very difficult conditions. Both locally and internationally there is a growing recognition that, as levels of mental illness continue to rise, clinical services which are already overburdened, will be increasingly unable to meet the need (Murray and

3 Palagi is the Samoan term for a New Zealander of European decent 
Lopez, 1996; MacDonald and O'Hara, 1998). However we also agree with the comment by Friedli (Friedli, 2001) to the effect that statistics about mental illness and problems provide nothing that is of utility in attempting to measure wellbeing. Population oriented public health approaches represent the main area of untapped potential in the face of the growing problem of mental illness (Ministry of Health, 1997b), especially given the broad range of influences upon mental health. A key hope appears to lie in the area of mental health promotion (Hart, 1999; Joubert and Raeburn, 1998b; MacDonald and O'Hara, 1998; Ministry of Health, 1997d) which, in the absence of coherent theory, has evolved around the application of the principles of the Ottawa Charter to the field. The other framework that we feel could be of value, particularly for young people, is the deliberately holistic approach of positive development (Durie, 1997; Forum for Youth Investment, 2001), which works toward enhancing human environments for health gains in this area.

Given that the funding and other resources currently available to the mental health sector in this country are already over-consumed, we welcome the recent re-allocation of mental health promotion development from the $\mathrm{MoH}$ mental health portfolio to its public health portfolio as a measure against destructive competition for funding. We believe it is imperative that there is a conceptual and fiscal separation so that new approaches can progress their different but congruent agendas to maximum effect. Lodging new paradigms within the existing framework of treatment and service provision runs the risk of obscuring the theory, goals and practices of the fledglings beneath the programmes and imperatives of the established sector. Against this background, our current research project Theorising Youth Mental Health Promotion (HRC grant 00/256) approaches mental health from a positive perspective. Our interest is in the health promoting features of the social and physical 
environments in which most Maori, Samoan and Pakeha ${ }^{4}$ young people in Manukau, most of the time thrive and grow. The other 'positive' aspect of this project is that the funder (HRC) has acknowledged and validated multi-level control in terms of Maori, Samoan and Pakeha/Palagi components at manager/researcher/researched levels, which enhances the capacity-building, collaborative and multidisciplinary elements of these groups. Moreover the shift away from pan-Pacific research and its homogenizing tendencies in favour of an ethnic-(s) Pacific focus on Samoan youth is an important feature of this project. We have gathered lifestory (Olsen and Shopes, 1991) interviews from 30 young people in each ethnic group and are analysing this large database for commonalities and variations in experience. It is not our intention to report on these issues in the current paper but we feel that themes emerging from the data we have gathered may indeed provide the raw materials from which measurements around the wellbeing of young people in our situation can be developed.

If terms such as wellness and such positive development sound utopian, perhaps this arises from the urgency of the current and imminent problems faced by communities and from the multi-faceted character of problems with mental illness. However unless we can bring new strategies to bear that reduce the population levels of mental health problems we will be left with the ongoing impacts of this flood tide. In order to support and refine interventions mental health promotion and positive development need conceptual space within which to develop and test theory and carry out evaluated demonstration projects.

\footnotetext{
${ }^{4}$ Pakeha is the Maori term for a New Zealander of European decent
} 
Western Theoretical bases of Approaches to Mental Illness

Western theorising of health in general and mental health in particular, reflects the mind-body dualism of Cartesian philosophy, emphasizing the primacy of the individual (as site of mind/body) and the validity of compartmentalizing human functioning into 'mental' and 'physical' dimensions. As such the theoretical structures of the medical model (Caplan, 1964) represent a top-down, intellectualized explanatory schema imposed upon the everyday interpretation of health experience. Established medical theory tends to conceptualise health as the absence of disease, such that ensuring health is seen mainly as dealing with disease processes. For example Caplan (Caplan, 1964) distinguishes between primary (prevention), secondary (problem reduction) and tertiary (impact minimisation) interventions; despite this apparent prioritising, medicine works mainly in the secondary and tertiary domains. Public health in which most of the prevention activity is focussed remains a poor cousin both conceptually and in terms of resource allocation.

A key distinction between medical and public health theory is a focus on individuals and risk factors as against a concern for populations and risk conditions. Risk factors are lifestyle behaviours or environmental exposures associated with particular illnesses (Higgins and Green, 1994) whereas risk conditions have been described as the shared contexts and structures that affect health of communities and populations (Hawe and Shiell, 2000).

Antonovsky (Antonovsky, 1987; Antonovsky, 1996) is critical of the focus on risk factors as indicative of an underlying adherence to a "pathogenic" model of health, which in turn stems from dichotomous categorisation of people into healthy and unhealthy classes. Aside from the strong evidence that most conditions of concern to 
health exist in continuous distributions through populations, (Rose, 1992) the weakness of such a model is that it assumes that the reduction or removal of risk factors will result in improved health. Syme (Syme, 1986) has criticised such models for the assumption that the targeting of “modifiable” factors, usually human characteristics, and individual behaviour change, represents the most efficacious pathway to population health.

The Maori, Samoan and positive youth development theories drawn upon in this paper conceptualise health in an alternative manner stressing the holistic, relational nature of people’s experiences of well-being, representing a 'grassroots' approach. For example a central concept in the Whare Tapa Wha framework (Durie, 1994) is the interconnection of elements concerned with Maori well-being. In this, the four walls of a house represent four dimensions (see page 7 below), each connected to each other and forming a whole. In Samoan conceptualisations the notion of 'Va'(Wendt, 1991) - the space between people, which at once joins and separates them - is a crucial unifying concept. In positive development, the notion that development is inextricably intertwined with the situational context is important. These and other aspects of these frameworks that ground and contextualise them in terms of lived experience are implicit in our critique of existing theorising of mental health promotion. Mental health promotion is an increasing focus of research, application and evaluation (Friedli, 1999; Hart, 1999) and is emerging as a new policy direction in many countries including Canada , Australia (Commonwealth Department of Health and Aged Care, 1999) and New Zealand (Ministry of Health, 1996b; Ministry of Health, 1997c). Analysis of these and other existing policy platforms (World Health Organization, 2001) reveals a theoretical orientation to medical models of mental health and a consequent focus on mental illness (Barry, 2001). As a consequence, the 
established medical model of health in a variety of conscious and incidental ways marginalises or discounts the value of population/environmental oriented public health approaches to the problems posed by the decay of mental health and the advance of mental illness.

While a number of commentators (MacDonald and O'Hara, 1998; Tudor, 1996) have pointed out a problematic elision of the terms prevention and promotion in this context much ambiguity remains over definitions. In the field of mental health, the most influential theoretical framework for interventions to reduce the impact and incidence of problems (Mrazek and Haggerty, 1994) focuses mainly on treatment and maintenance (ie secondary and tertiary interventions). Prevention is seen mainly in terms of attempting to minimise the risk factors faced by individuals by various targeted interventions while promotion entails a "focus on health rather than illness" (p27). Indeed these authors while acknowledging that mental health promotion is “important and widespread”, state specifically that their model does not encompass it and deal with the issues in a separate chapter. Although this provides coverage of “alternative” (including anthropological accounts of systems used by indigenous peoples) bases for producing and enhancing the well-being of groups, mental health promotion remains severely under-theorised.

Scrutiny of Mrazek and Haggerty's model confirms its orientation toward treatment and various forms of targeted prevention. It envisages a spectrum of responses to mental illness in which three sectors signal possible actions - maintenance, treatment and prevention. Maintenance and treatment deal specifically with responses that work with unwell individuals while prevention consists of indicated, selected and universal interventions. Selected and universal interventions are specified as risk factor approaches that target individuals or groups. The universal category is defined as 
measures "targeted to the general public or a whole population group that has not been identified on the basis of individual risk factors” (p24). Finally, the full title of the framework diagram is given as "The Institute of Medicine mental health intervention spectrum for mental disorders" confirming that the main concern is treatment and prevention of mental disorder rather than the promotion of mental health.

This analysis alone highlights the extent to which this framework is about treatment options that are based on risk factors and changing human behaviours rather than human environments. On this basis we would question the extent to which this can be called a mental health promotion framework. The only possible space for health promotion activities is within the "universal" prevention category but consideration of examples offered of such interventions (parenting programmes, childhood immunization and marriage counseling) reveals a focus on changing individuals rather than a programme of population oriented environmental change for health gain. Joubert and Raeburn (Joubert and Raeburn, 1998a) also endorse a demarcation between pathologising prevention approaches working to enhance "resilience in supportive environments” (p15) commending approaches in the spirit of the Ottawa charter of capacity-building for community empowerment. However the focus is defacto on the individual whose "resilience ... the capacity to cope with and bounce back" from the trials of life, is to be "nurtured" by access to "supportive resources". Latterly Raeburn (Raeburn, 2001) has moved to shift the focus from the individual by modifying the key concept of resilience to reassert the importance of community approaches to mental health promotion.

Barry (Barry, 2001) takes up the challenge of theorising mental health promotion implicit in Mrazek and Haggerty’s (Mrazek and Haggerty, 1994) work, 
supplementing their half circle of prevention, maintenance and treatment and completing the circle by offering the missing half as mental health promotion interventions focussed on competence, resilience, supportive environments and empowerment. Crucially she places "strategies for promoting wellbeing and quality of life" at the centre of the circle thus steering away from a problematic individualising of the framework and maintaining the focus on population strategies. In terms of policy and strategy we are impressed by the Australian National Mental Health Strategy (Commonwealth Department of Health and Aged Care, 1999), which spells out some differences between promotion and prevention. The latter is concerned with "individuals prior to the onset of a disorder" (p3) while mental health promotion is defined as working to improve social, physical and economic environments and enhancing the capacity of communities in ways that can contribute to the community/population mental health. MHP is thus built upon the idea of building mental wellbeing rather than prevention of mental illness.

The New Zealand Ministry of Health paper Mental Health Promotion (Ministry of Health, 1997b) provides a clear definition of prevention as simply the reduction of incidence and prevalence of mental illness by means of primary, secondary and tertiary measures. The latter two are treatment options while primary prevention is described as "the protection of health by personal and community-wide efforts". The approach to promotion is cast in terms of enabling people and communities to control and improve their own health through strategies suggested by the Ottawa Charter. There is a linkage between promotion and prevention in that the former, through the development of community capacity and social support, may alleviate stress and mental illness symptoms and produce positive impacts on prevalence and incidence. Where prevention is about reduction of mental illness as identified by professionals, 
promotion is about achieving health goals set by communities. However the discussion of the possibilities for promotion concludes that primary prevention strategies based in community development approaches are unlikely to be effective in the short or medium term and that, while possible for common disorders, there is “insufficient knowledge” to develop primary prevention for "severe mental disorders" (p7). Again the problem is in the bending of the focus back onto illness rather than keeping a balance with the benefits that flow from community development. The recently disseminated consultation document Building on Strengths (Ministry of Health, 2001) focuses such ideas as an appropriate basis for the development of appropriate national mental health promotion strategy for Aotearoa/New Zealand. For example while the costs and stresses for individuals, families and communities of mental illness are recognized and catered for, most of the emphasis is upon creating and maintaining healthy communities as the most effective and desirable way of producing positive mental health outcomes. Building social and physical infrastructure through concentrating on participation, leadership, resources and cooperation is seen as critical to mental health promotion.

\section{Social epidemiology of mental health}

Social epidemiology shows that both historically (Macintyre, 1997; Szreter, 1997) and in the contemporary setting (Rose, 1992; Marmot, 1998) environmental public health measures have made the most significant contributions to improvements in population health. The study and theorising of population approaches to health issues (Berkman and Kawachi, 2000; McMichael, 1993) suggests that since the primary determinants of disease are economic and social, solutions should be sought in these dimensions. The discipline predicts and demonstrates that, while such environmental interventions 
may yield only small gains for individuals, they can build into major advances for populations.

In relation to this so-called "prevention paradox", Rose (Rose, 1992) has suggested that population strategies are indicated wherever a continuum of risk is widely diffused through a population, as is the case with mental illness. For example in a study of depression (Brenner, 1975) demonstrates the relative merits of population approaches compared to those targeting only the most severely affected. The analysis of the proportion of cases falling above the diagnostic cutoff in the continuum of symptomatology shows a quarter of cases above the threshold and the remainder below.

Given that people with any symptoms require support (ie incur costs to their personal networks and society) the community benefits more by working with the mass with lesser symptoms than by working with the minority with clinically defined depression.

A further study (Anderson et al, 1993) showed that scores on the CGHQ (Chronic General Health Questionnaire), when applied to a large British sample fall on a continuum, with approximately $30 \%$ of the sample above the psychiatric diagnostic cutoff. Of these cases there were clear correlations attributable to gender, region, income and class. Thus social epidemiology is central to understanding and addressing the environmental and population determinants of mental illness. It provides a research based rationale for interventions designed to improve the overall state of mental health of a population. However while there are various avenues leading away from the focus on illness and problems within the discipline (for example the establishment of the continuum of symptoms in the case of depression) there is as yet no social epidemiology of well-being, happiness or positive 
development. In contrast Maori and Samoan conceptualizations of health and wellbeing from Aotearoa/New Zealand are in effect much broader than western models and therefore have much to offer as a basis for theorizing mental health promotion. The reason that such valuable insights have been obscured to the world is in part that colonial processes that have controlled development in this country have marginalized these theories so they have not been seen as a viable resource by the populations concerned to protect themselves from the complex stressors that result in mental illness. We offer a brief outline of key dimensions of such indigenous theorising.

\section{New Directions: Holistic houses of health}

\section{Maori models of well-being}

Maori concepts of health are generally described as holistic and this theme is echoed throughout indigenous discussions on health. Drawing on Maori knowledge some models of well-being have emerged and been described in various writings (Durie, 1994; Pere, 1997). While there are a number of models and critiques of these models, the underlying theme is that health cannot be separated out from other dimensions of people and their world. Thus Maori concepts of health are generally termed holistic and encompass aspects such as wairua (spiritual), hinengaro (mental), tinana (physical), taiao (environmental), taha tikanga (cultural), and whanau, whakapapa and whenua (family and land). The interaction of these dimensions is also crucial in the well-being of people. Included in these concepts is an understanding of how colonisation and inequity can impact on all aspects of health in its broadest sense. The metaphor of the house used in the Whare Tapa Wha model (Durie, 1994), in which the upright poles of the house are necessary to ensure strength and symmetry while representing the four dimensions of taha wairua (spiritual side), taha hinengaro 
(thoughts and feelings), taha tinana (physical side), and taha whanau (family), stresses the essential integration of the crucial dimensions of well-being.

This model (Durie, 1994) encompasses spirituality and is useful in exploring how identity and alienation through colonisation may affect health. The relationship between people and their environment and whanau is one of the concepts encompassed by this model that has implications for mental health promotion. In addition, the well-being of whanau is affected if one member is not well and this impacts on everybody (Oral reference, Kaumatua, South Auckland). Te Pae Mahutonga (Durie, 1999) brings together the elements of modern health promotion in a cohesive manner by referring to a well-known celestial body, te Pae Mahutonga. These stars, otherwise known as the Southern Cross, are important navigational guiding points. The constellation is used as a symbolic map for bringing together the significant components of health promotion in a Maori framework. The bright stars of health promotion are, mauriora (access to te ao Maori), waiora (environmental protection), toiora (healthy lifestyles), and te oranga (participation in society). Durie states that if this framework is to be successful, then the two crucial challenges to New Zealand society are leadership and autonomy for Maori in health promotion development and strategies.

These frameworks, where well-being rests on the balance of a number of inter related factors, carry the implicit idea that conditions that determine quality of life can be either health promoting or health demoting (Durie, 1997). Equally there is an imperative that, to address inequities among the well-being of populations, projects and policies must address these multiple dimensions (Health Funding Authority, 1999). 


\section{Pacific Models of “Well-being”}

The concept of the Samoan self as a "relational self" is explicit in the literature on Samoan well-being (Tamasese et al, 1997) . The Samoan self is described as reliant on relationships that are occurring in the va, or "space between"--between the self and parents, siblings, grandparents, aunts and uncles, other extended aiga (extended families) members in New Zealand, the homeland and abroad, church/neighbourhood communities, friends, peers, and wider New Zealand society. It is in this relational space that new personal, cultural, social and economic structures of social mobility, ethnicity, gender, identity and well-being, are being wrought. It is here - in between relatives, aiga, and other people in one's environment - that one can understand the centrality of ethnic identity and well-being that is so necessary for positive health gains (Anae, 1998).

What is required now is a move away from macro analyses of mental health to a focus on ethnic-specific experiences/contexts of life experiential events - with emphasis on individuals, their families and groups and their understandings of their lived experiences and realities of their situations. For young peoplehe $v a$ that we are most interested in lies in the spaces between youth and all others who impact on their 'environment' to understand the realities and complexities of mental health and wellbeing in the "spaces" in between.

Two significant models of Pacific health and well-being have emerged in the literature. They are the "Fonofale" model (Ministry of Health, 1997a), and the "Fa'afaletui" model (Tamasese et al, 1997). Both models are representations of health from a Samoan perspective and are based on the concept of fale, the traditional Samoan house. The Fonofale model specifically relates to the traditional Samoan meeting-house and the Fa'afaletui model represents the critical process of weaving 
(tui) together all the different levels of knowledge frames from within the 'houses' of collective representation, in order that the Samoan world view is substantially enhanced.

The Fonofale model describes the roof as representing cultural values and beliefs (which include traditional as well as western methods of healing), which are the shelter for life. The foundation represents the nuclear as well as the extended family and kin group and forms the fundamental basis for social organisation. The family provides the base of the house which supports the four pou (house-posts) - the physical-biological well-being, the spiritual or the sense of well-being which stems from a belief system which includes christianity or traditional spirituality relating to nature, language beliefs and/or history, the mental or the health of the mind which involves thinking and emotion, and lastly the other which includes variables such as gender, sexual orientation, age, social class and other aspects. Surrounding the fonofale is the context in which health occurs in terms of time, context and environment: for example, New Zealand-based and not island-based; the time period; and the environment - rural, village, urban.

The Samoan fonofale and fa'afaletui models thus incorporate the environmental, the social and psychological - the roof and foundation of the fale - representing culture and family. These encompass dimensions of physicality, spirituality, mentality, and other dimensions, which are in turn surrounded by aspects of time, context and environment. Together these dimensions represent the optimum conditions for mental health and are therefore by definition health promoting. By implication, negative experiences of any of these conditions would constitute a health-demoting environment. 
From these frameworks, the importance of mental health promotion for Samoan people lies in the strengthening of spirituality and the relational arrangements within the family, in recognition that the family is the first place of relational harmony, belonging and identity. These relational arrangements flow outwards to the Samoan community in which the church plays a crucial part, culminating in roles and responsibilities within the wider community of New Zealanders. Moreover, for NZborn Samoans, which represent over 50\% of the Samoan population in New Zealand, it involves the exposure, understanding and reconciliation of their positioning in New Zealand society and the framing of their identity journeys (Anae, 1998).

Maori and Samoan frameworks of mental health have common themes around the holistic, multilevel, multi-faceted nature of mental health and well-being. They recognise the importance of developmental and life-stage dimensions and highlight the importance of culture, and social relations. They acknowledge that economic and political power is part of the mix. They stress the role of community environments as health promoting or health demoting for individuals and communities.

\section{Youth development}

Taking the Maori and Pacific models outlined above as an inspiration for new directions in thinking about mental health, it is timely to be looking at the development of theory for youth well-being within a public health framework. This holistic approach is echoed in research on positive development (Pittman et al., 2001; Roth and Brooks-Gunn, 2000) where the determination to take a broader approach to human experience has emerged. Within this paradigm early research on resilience (Rutter, 1987) has expanded to focus diverse studies on the social environments of young people (Blum, 1998; Blum and Rinehart, 1997; Resnick, 2000). These have 
contributed to the realisation that absence of problems does not mean that adolescents are fully prepared for their future (Pittman, 2001), which implies that proactive approaches must take a programmatic stance on development that works to enhance the positive factors and minimise the negative factors in the life environments of young people. While resiliency may be seen as a characteristic of individuals, research also emphasises that the context within which such resilience occurs is the social environment (Blum, 1998; Blum and Rinehart, 1997)

Roth and Brooks-Gunn (Roth and Brooks-Gunn, 2000) provide an overview of research findings from within the positive development framework on the multiple contexts in which adolescents develop. Key aspects of family, peer group, school, workplace and neighbourhood that wield positive and negative influences and effect outcomes accordingly are described. Attributes of successful youth development programmes, especially the orientation to young people that regards them as assets rather than liabilities, are canvassed. They conclude that positive development can be promoted through the co-ordinated actions of all sectors of the community particularly if there is consensus on the "value and potential of all youth". Therefore approaches that seek to move beyond problem-centred responses to youth require careful and fulsome investment in social environments.

\section{Conclusion}

In the development of the national strategy for mental health promotion there exists an opportunity to step outside the boundaries of Western theorising of mental illness and incorporate Maori and Pacific models of well-being - holistic houses of health - in reappraising the utility of the public health framework for this crucial and pressing 
concern. We acknowledge that treatment and prevention approaches will always be necessary and will undoubtedly be of crucial importance in the short to medium term. Both locally and internationally there is growing interest in positive development paradigms as a way of at once optimising human development and preventing and reducing the persistent and debilitating social and fiscal costs associated with mental illness and the associated problems. While there are common goals, we are not certain that public health and health promotion approaches are synonymous with positive development. We suggest that serious consideration of positive development paradigms reflected in Maori and Pacific approaches to mental health as a base for theory and policy aimed at enhancing the wellbeing of young people, may reduce the level of need for mental health services. In addition they can be expected to produce outcomes that supplement and extend gains in population mental health achieved through health promotion.

\section{References}

Albee, G. (1992) Keynote speech. In: Trent, D. and Reed, C. (Eds.) Promotion of mental health. Avebury: Ashgate.

Anae, M. (1998) Fofoa-i-Vao-'Ese: The Identity Journeys Of NZ-Born Samoans, Doctoral. Department of Anthropology, University of Auckland.

Anae, M. (1999) Preliminary Findings on the Mental Health of Pacific Islands People in New Zealand From a Literature Review Undertaken by way of HRC Seeding Grant Auckland: Department of Anthropology, University of Auckland.

Anderson, J., Huppert, F. \& Rose, G. (1993) Normality, deviance and minor psychiatric morbidity in the community. A population-based approach to the General Health Questionnaire data in the Health and Lifestyle Survey. Psychological Medicine 23 475-485.

Antonovsky, A. (1987) Unraveling the Mystery of Health. San Francisco: Jossey Bass.

Antonovsky, A. (1996) The salutogenic model as a theory to guide health promotion. Health Promotion International 11 11-18. 
Barry, M. (2001) Mental health promotion: perspectives and practices. International Journal of Mental Health Promotion 3 4-12.

Bathgate, M. (1994) The Health of Pacific Islanders in New Zealand. Wellington: Ministry of Health.

Berkman, L. \& Kawachi, I. (2000) Social Epidemiology. Oxford: Oxford University Press.

Blum, R. (1998) Healthy youth development as a model for youth health promotion. Journal of Adolescent Health 22 368-375.

Blum, R. \& Rinehart, P. (1997) Reducing the Risk: Connections That Make a Difference in the Lives of Youth. Minneapolis, MN: Division of General Pediatrics and Adolescent Health, University of Minnesota.

Brenner, M. (1975) Trends in alcohol consumption and associated illnesses: some effects of economic changes. American Journal of Public Health 65 1279-1292.

Caplan, G. (1964) Principles of Preventive Psychiatry. New York: Basic Books.

Charlesworth, A. \& Nathan, R. (1987) Stress Management. Auckland: Transworld Publishers.

Commonwealth Department of Health and Aged Care (1999) Mental Health Promotion and Prevention National Action Plan. Canberra: Commonwealth of Australia.

Dawson (1988) Maori admissions under the Mental Health Act. In: Maori Mental Health: A Resource Kit . Auckland: Mental Health Foundation of New Zealand.

Disley, B. (1996) Reducing the Risk of Mental Disorder and Suicide: Public Health Strategies. Wellington: Winston Churchill Memorial Trust Board.

Druss, B., Marcus, S., Rosenheck, R., Olfson, M., Tanielian, T. \& Pincus, H. (2000) Understanding disability in mental and general medical conditions. American Journal of Psychiatry 157 1485-1491.

Durie, M. (1994) Whaiora: Maori Health Development. Auckland: Oxford University Press.

Durie, M. (1997) Puahou: a five point plan for improving Maori mental health. In: Maori Mental Health Summit.

Durie, M. (1999) Te Pae Mahutonga: a model for Maori health promotion. In: Health Promotion Forum Conference, Napier.

Dyall, L. (1997a) Hauora o te Hinengaro: pathway to Maori mental health and wellness: report of the Hui Hauora Hinengaro. Auckland: Health Research Council of New Zealand. 
Dyall, L. (1997b) Maori, in: Ellis, P. and Collings, S. (Eds.) Mental Health in New Zealand From a Public Health Perspective. Wellington: Public Health Group, Ministry of Health.

Evans, J. \& Repper, J. (2000) Employment, social inclusion and mental health. Journal of Psychiatric and Mental Health Nursing 7 15-24.

Forum for Youth Investment (2001) Aligning Youth Agendas: A Rationale for the Forum for Youth Investment. Forum for Youth Investment.

$<$ http://www.forumforyouthinvestment.org $>$

Friedli, L. (1999) From the margins to the mainstream: the public health potential of mental health promotion. International Journal of Mental Health Promotion 1 30-36.

Friedli, L. (2001) Mental health promotion: perspectives and practices. International Journal of Mental Health Promotion 3 20-24.

Hart, B. (1999) What public health could (belatedly) contribute to mental health promotion. International Journal of Mental Health Promotion 1 22-29.

Hawe, P. \& Shiell, A. (2000) Social capital and health promotion: a review. Social Science and Medicine 51 871-855.

Health Funding Authority (1999) Kia Tu Kia Puawai: Mental Health. Wellington: Health Funding Authority.

Health Funding Authority (2000) Striking a Better Balance: A Health Funding Response to Reducing Inequalities in Health, August. Wellington: Health Funding Authority.

Herron, S. \& Trent, D. (2000) Mental health: a secondary concept to mental illness. International Journal of Mental Health Promotion 2 29-38.

Higgins, J. \& Green, L. (1994) The APHA criteria for development of health promotion programs applied to four Healthy Community projects in British Columbia. Health Promotion International 9 311-320.

Joubert, N. \& Raeburn, J. (1998a) Mental health promotion: people, power and passion. International Journal of Mental Health Promotion 1 15-22.

Joubert, N. \& Raeburn, J. (1998b) Mental health promotion: problems and possibilities. International Journal of Mental Health Promotion 1 15-22.

Kelsey, J. (1993) Rolling Back the State: Privatisation of power in Aotearoa/New Zealand. Wellington: Bridget Williams Books.

Kessler, R., Berglund, P., Foster, C., Saunders, W., Stang, P. \& Walters, E. (1997) Social consequences of psychiatric disorders, II: Teenage parenthood. American Journal of Psychiatry 154 1405-1411. 
Kessler, R., Foster, C., Saunders, W. \& Stang, P. (1995) Social consequences of psychiatric disorders, 1: Educational attainment. American Journal of Psychiatry 152 1026-1032.

Kessler, R., Walters, E. \& Forthofer, M. (1998) The social consequences of psychiatric disorders, III: probability of marital stability. American Journal of Psychiatry 155 1092-1096.

MacDonald, G. \& O'Hara, K. (1998) Ten Elements of Mental Health, its Promotion and Demotion: Implications or Practice: Society of Health Education and Promotion Specialists Position Paper on Mental Health Promotion. Birmingham: School of Health and Policy Studies, University of Central England.

Macintyre, S. (1997) The Black Report and Beyond: What are the Issues? Social Science and Medicine 44 723-745.

Marcotte, D. \& Wilcox-Gok, V. (2001) Estimating the employment and earnings costs of mental illness: recent developments in the United States. Social Science and Medicine 53 21-27.

Marmot, M. G. (1998) Improvement of social environment to improve health. The Lancet 351 57-60.

McMichael, A. J. (1993) Planetary Overload: Global Environmental Change and the Health of the Human Species. Cambridge: Cambridge University Press.

Mental Health Commission (1998) Blueprint for Mental Health Services in New Zealand. Wellington: Mental Health Commission.

Mental Health Commission (1999) New Zealand's National Mental Health Strategy: Review of Progress 1994-1999. Wellington: Mental Health Commission.

Ministry of Health (1996a) Mason Report: Inquiry Under Section 47 of the Health and Disability Services Act 1993 in Respect of Certain Mental Health Services : Report / of the Ministerial Inquiry to the Minister of Health Hon. Jenny Shipley. Wellington: Ministry of Health.

Ministry of Health (1996b) Youth Mental Health Promotion. The Public Health Issues 1995-1996. Wellington: Ministry of Health.

Ministry of Health (1997a) Making a Difference: Strategic Initiatives for the Health of Pacific People. Wellington: Ministry of Health.

Ministry of Health (1997b) Mental Health in New Zealand From a Public Health Perspective. Wellington: Ministry of Health.

Ministry of Health (1997c) Moving Forward: The National Mental Health Plan - For More and Better Services. Wellington: Ministry of Health. 
Ministry of Health (1997d) Progress on Health Outcome Targets: Te Haere Whakamua Ki Nga Whainga Hua Mo Te Hauora: The State of the Public Health in New Zealand. Wellington: Ministry of Health.

Ministry of Health (1999) Youth Suicide Facts: 1997 Statistics. Wellington: Ministry of Health.

Ministry of Health (2001) Building on Strengths: A Springboard for Action. A New Approach to Promoting Mental Health in New Zealand/Aotearoa. Wellington:

Ministry of Health.

Ministry of Youth Affairs (2001) Supporting the Positive Development of Young People in New Zealand: A Discussion Document for Consultation on a Youth Development Strategy Aotearoa. Wellington: Ministry of Youth Affairs. $<$ http://www.youthaffairs.govt.nz/pag.cfm?i=150>

Mrazek, P. \& Haggerty, R. (1994) Reducing Risks for Mental Disorders: Frontiers for Preventive Intervention Research. Washington, DC: National Academy Press.

Murray, C. \& Lopez, A. (Eds.) (1996) The Global Burden of Disease and Injury. World Health Organization/World Bank.

Olsen, K. \& Shopes, L. (1991) Crossing boundaries, burning bridges: doing oral history with working class men and women. In: Gluck, S. \& Patai, D. (Eds) Women's Words pp189-204. London: Routledge.

Pere, R. (1997) Te Oranga o te Whanau: the health of the family. In: Hui Whakaoranga: Maori Health Planning Workshop, Wellington.

Pittman, K., Irby, M. \& Ferber, T. (2001) Unfinished Business: Further Reflections on a Decade of Promoting Youth Development. Takoma Park: Forum for Youth Investment. <http://www.forumforyouthinvestment.org>

Raeburn, J. (2001) Community approaches to mental health promotion. International Journal of Mental Health Promotion 3 13-19.

Resnick, M. (2000) Resilience and protective factors in the lives of adolescents. Journal of Adolescent Health 27 1-2.

Rose, G. (1992) The Strategy of Preventive Medicine. Oxford: Oxford University Press.

Roth, J. \& Brooks-Gunn, J. (2000) What do adolescents need for healthy development? Implications for youth policy. Social Policy Report 14 3-19.

Rutter, M. (1987) Psychosocial resilience and protective mechanisms. American Journal of Orthopsychiatry 57 316-331.

Smith, L. (1998) Towards the new millenium: international issues and projects in indigenous research in: Durie, M., Cunningham, C., Olson, R., Coupe, N., Waldon, J., 
Gillies, A. and Taite, S. (Eds.) Te Oru Rangahau: Maori Research and Development Conference Proceedings, pp12-31. Palmerston North: School of Maori Studies, Massey University.

Stephens, T. (1998) Population Mental Health in Canada. Ottawa: Mental Health Promotion Unit, Health Canada.

Syme, S. (1986) Strategies for health promotion. Preventive Medicine 45 492-507.

Szreter, S. (1997) Economic growth, disruption, deprivation, disease and death: on the importance of public health for development. Population and Development Review 23 693-728.

Tamasese, K., Peteru, C. \& Waldegrave, C. (1997) The New Morning: A Qualitative Investigation Investigation into Samoan Perspectives on Mental Health and Culturally Appropriate Services. Lower Hutt: The Family Centre.

Te Pumanawa Hauora (1995) Guidelines for purchasing personal mental health services for Maori. Palmerston North: Department of Maori Studies, Massey University.

Tudor, K. (1996) Mental Health Promotion: Paradigms and Practice. London: Routledge.

VicHealth (1999) VicHealth Letter Issue 11 Autumn.

Wendt, A. (1991) Ola. Auckland: Penguin Books.

Wittchen, H., Nelson, C. \& Lachner, G. (1998) Prevalence of mental disorders and psychological impairments in adolescents and young adults. Psychological Medicine 28 109-126.

Woodward, L. \& Fergusson, D. (2001) Life course outcomes of young people with anxiety disorders in adolescence. Journal of the American Academy of Child \& Adolescent Psychiatry 40 1086-1093.

World Health Organization (2001) Mental Health: A Call for Action by World Health Ministers. Geneva: World Health Organization. 